\title{
Mehr als nur ein Porträt
}

\section{Matthias Scholer}

Dr., Online-Redaktor

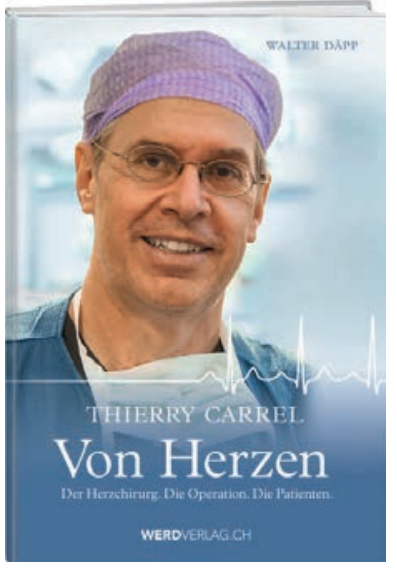

Walter Däpp

Thierry Carrel - Von Herzen

Der Herzchirurg. Die Operation. Die Patienten.

Thun: Werd \& Weber Verlag, 2015.

212 Seiten, 32 CHF.

ISBN 978-3-85932-762-7

«Carrel operierte mich, setzte mir fünf Bypässe ein und holte mich so ins Leben zurück», erzählt alt Bundesrat Hans-Rudolf Merz im Vorwort des im Herbst erschienenen Buchs Thierry Carrel - Von Herzen. Der Autor Walter Däpp gliedert das Werk in drei Teile: Der Herzchirurg, die Herzoperation und die Patienten. Abgerundet wird das Werk mit einem Nachwort von Professor Ulrich Althaus, dem Vorgänger Carrels am Berner Inselspital.

\section{Von Leidenschaft, Kultur und Neidern}

Im ersten Teil porträtiert Walter Däpp den renommierten Chirurgen aus ganz verschiedenen Blickwinkeln. So lernen die Leser Thierry Carrel nicht nur als Herzchirurgen aus Leidenschaft und Teamplayer, sondern auch als kunst- und kulturbeflissenen Menschen und Musiker kennen. Der Autor lässt dafür neben dem Hauptprotagonisten auch seine beruflichen Weggefährten und seine Familie zu Wort kommen. Dabei erfährt man viel Persönliches. Sei es Carrels Einstellung zu Leben, Tod und Sterbehilfe. Oder wie Neider versuchten, dem aufstrebenden Herzchirurgen Steine in den Weg zu legen. Die Offenherzigkeit, mit der Thierry Carrel Einblicke in sein Leben und seine Persönlichkeit gewährt, lässt die Leser den Menschen spüren, der fast tagtäglich seine ganze Energie seiner Berufung, seinem Beruf und damit den Patienten zugutekommen lässt.

\section{Wechselwirkung zwischen Arzt und Patient}

Im zweiten Teil nimmt Walter Däpp die Leser mit in einen Operationssaal des Berner Inselspitals, in dem Carrel einen Eingriff am offenen Herzen durchführt. Der Autor schildert dabei für Laien interessante Details wie beispielsweise das reibungslos funktionierende Zusammenspiel des Operationsteams und den Einsatz modernster Technik.

\section{Patientengeschichten}

Diese Reportage aus dem Operationssaal leitet zum dritten Teil des Buchs über, in dem zwanzig Patientinnen und Patienten von ihren Herzleiden, ihren Ängsten, der fürsorglichen Betreuung durch Carrel und sein Team und ihrem Leben nach dem Eingriff erzählen. Jede dieser Geschichten kommentiert Thierry Carrell abschliessend aus seiner Sicht, wobei auch die wichtigsten klinischen und diagnostischen Befunde des jeweiligen Falls aufgeführt werden.

\section{Fazit}

Das Buch Thierry Carrel - Von Herzen beleuchtet nicht nur den Menschen und Arzt Carrel aus verschiedenen Blickwinkeln. Es soll auch Herzpatienten, bei denen eine Operation am offenen Herzen bevorsteht, $\mathrm{Zu}$ versicht spenden und ihnen helfen, über ihre Sorgen und Ängste zu sprechen. Oder wie es Professor Ulrich Althaus im Nachwort ausdrückt: «Mir persönlich war immer etwas unheimlich zumute, wenn ein Patient am Vorabend der Operation den Helden spielte und versicherte, er fühle sich wie vor dem Gang zum Coiffeur.» 